\title{
TAX AND SUBSIDY COMBINATIONS FOR THE CONTROL OF CAR POLLUTION
}

\author{
Don Fullerton \\ Sarah E. West \\ Working Paper 7774 \\ http://www.nber.org/papers/w7774
NATIONAL BUREAU OF ECONOMIC RESEARCH 1050 Massachusetts Avenue Cambridge, MA 02138
July 2000

We are grateful for helpful comments from Michael Greenstone, Suzi Kerr, Arik Levinson, Raymond Robertson, Dan Slesnick, Ken Small, Pete Wilcoxen, Paul Wilson, Ann Wolverton, and participants at various seminar presentations. For programming suggestions, we thank Jonathan Caulkins, Dan Gaynor, and David Kendrick. For data, we thank the California Air Resources Board, Satya Devesh, Mary Hostak, and Raphael Susnowitz. In addition, we would like to thank the Public Policy Institute of California (PPIC) for funding this research. This paper is part of the NBER's research program in Public Economics. Any opinions expressed are those of the authors and not those of the PPIC or the National Bureau of Economic Research.

(C) 2000 by Don Fullerton and Sarah E. West. All rights reserved. Short sections of text, not to exceed two paragraphs, may be quoted without explicit permission provided that full credit, including $(\mathrm{C}$ notice, is given to the source. 
Tax and Subsidy Combinations for the Control of Car Pollution

Don Fullerton and Sarah E. West

NBER Working Paper No. 7774

July 2000

JEL No. H23, H21, Q21, Q28

\begin{abstract}
Despite technological advances, an individual car's emissions still cannot be measured reliably enough to impose a Pigovian tax. This paper explores alternative market incentives that could be used instead. We solve for second-best combinations of uniform taxes on gasoline, engine size, and vehicle age. For 1,261 individuals and cars in the 1994 Consumer Expenditure Survey, we record the car's model, year, and number of cylinders. We then seek a corresponding car in data from the California Air Resources Board that shows the car's engine size, fuel efficiency, and emissions per mile. We calculate the welfare improvement from a zero-tax scenario to the ideal Pigovian tax, and we find that 71 percent of that gain can be achieved by the second-best combination of taxes on gas, size, and vintage. A gas tax alone attains 62 percent of that gain. These results are robust to variation in the elasticity of substitution among goods.
\end{abstract}

Don Fullerton

Department of Economics

University of Texas at Austin

Austin, TX 78712

and NBER

dfullert@eco.utexas.edu
Sarah West

Department of Economics

Macalester College

1600 Grand Avenue

Saint Paul, MN 55105

wests@macalester.edu 
Despite decades of progress in reducing air pollution, several major urban centers in the United States still have not reached mandated pollution reduction. Ten metropolitan areas are listed in the extreme or severe categories of ozone non-attainment. ${ }^{1}$ Vehicles are the source of much of this pollution: they contribute 33 percent of volatile organic compounds, 41 percent of oxides of nitrogen, and 67 percent of carbon monoxide emissions in the United States (USEPA, 1989). In addition, light trucks are expected to be the "fastest growing source of global warming gases in the United States over the next decade" (Bradsher, 1997, p. A25).

A tax per unit of emissions would induce all of the cheapest forms of pollution abatement (Pigou, 1932), but the technology is not yet available to measure each car's emissions in a reliable and cost-effective manner. On-board diagnostic equipment is too costly because millions of vehicles would need to be retrofitted (Harrington et al., 1994). Remote sensing is inexpensive, but it cannot "distinguish unambiguously the car that is dirty on the average from the car that is clean on the average" (Sierra Research, 1994, p. 17). Thus, several papers explore market incentives that could be used in place of such a tax. ${ }^{2}$ With homogeneous agents, these papers show that the efficiency of the emissions tax can be achieved by a set of uniform tax or subsidy rates on choices such as fuel use, type of fuel, engine size, vehicle age, and pollution control equipment (PCE). With heterogeneous agents, results are more complicated.

In this paper, we develop both analytical and numerical models of heterogeneous agents who maximize different utility functions and thus make different choices about miles driven, engine size, and vehicle age - three important determinants of emissions. First, we extend the analytical model of Fullerton and West (2000) to include all three of those choices, using general

\footnotetext{
1 As of August 1999, an "extreme" rating was assigned to Los Angeles, and "severe" ratings were given to Baltimore, Chicago, Houston, Milwaukee, New York, Philadelphia, Sacramento, Ventura County, and the Southeast Desert Modified AQMA, CA. Updates can be found on the EPA webpage at http:/www.epa.gov/oar/oaqps/greenbk.

${ }^{2}$ For a few examples, see Mills and White (1978), Eskeland (1994), Eskeland and Devarajan (1996), Innes (1996), Kohn (1996), Harrington et al. (1998), Plaut (1998), and Sevigny (1998).
} 
functional forms, and we find that the first-best requires that each individual pay a different rate of tax on each such choice. ${ }^{3}$ Assuming such rates are not feasible, then, uniform rates are second best, and their efficiency must depend on the degree of heterogeneity in the population. That model provides no closed-form solutions for the second-best uniform tax rates.

Second, therefore, we assign specific functional forms and use data on 1,261 different consumers to estimate the parameters of a numerical version of that model. We simulate a notax baseline and the welfare gain from a first-best Pigovian tax. We then simulate a variety of more-feasible tax combinations, finding the welfare-maximizing uniform tax rates on choices such as gasoline, engine size, and vehicle age. Thus, we solve numerically for second-best tax rates. Despite considerable heterogeneity in our model, some combinations of uniform taxes perform quite well. We find that 71 percent of the gain from the Pigovian tax can be achieved by the combination of all three uniform tax rates. A gas tax alone reaches 62 percent of the Pigovian gain. These results are robust to changes in the elasticity of substitution among goods.

To parameterize this numerical model, we start with data on gasoline and other expenditures from the 1994 Consumer Expenditure Survey (CEX), data that include each car's make, model, year, and number of cylinders. For each such car, we look for an exact match in data on cars tested by the California Air Resources Board (CARB) Light-Duty Surveillance Program (Series 13). The combined data set is unique, as it includes each individual's expenditures, miles driven, vehicle age, miles per gallon $(M P G)$, emissions per mile $(E P M)$, and engine size measured in cubic inches of displacement (CID). We also use the CARB data to estimate $M P G$ and $E P M$ as nonlinear functions of engine size and vehicle age. We then use those estimated functions in later simulations of alternative policies - when consumers change their choices of engine size and vehicle age - to determine changes in fuel efficiency and emissions rates. Consumers also change their choices of miles $(m)$, so we can calculate the new

${ }^{3}$ A similar result for firms is found by Hoel (1998, p.90). 
emissions $(m \cdot E P M)$ as well as the new level of social welfare for each policy.

Actual vehicle emissions depend not only on vehicle size and age, but on qualities of the fuel, maintenance of the car's PCE, frequency of cold start-ups, temperature of the air, speed of the vehicle, and aggressive driving. ${ }^{4}$ Even tailpipe devices miss some emissions, especially evaporative emissions. If a tax on actual emissions is not feasible, authorities might be able to measure the emissions rate of each vehicle once each year and multiply by miles driven during the year. That policy might be difficult to enforce as well, if consumers can roll back their odometers..$^{5}$ The basic problem is that neither $m$ nor EPM is an observable market transaction. In contrast, an excise tax can be collected by the retailer and verified by an invoice.

In this paper, we have no data on driving speed, aggressive driving, cold start-ups, fuel characteristics, or PCE maintenance. ${ }^{6}$ Thus we treat $m \cdot E P M$ as the car's "true" emissions, and we treat a tax on those emissions as the "ideal" Pigovian tax. Still, our model allows us to use a variety of taxes or subsidies on observable choices such as gasoline, engine size, and vehicle age to induce individuals to drive fewer miles, to buy smaller cars, or to scrap older cars.

Existing regulations are not explicit in our model, but they are implicit in our data. That

4 More volatile gasoline leads to more evaporative emissions. The addition of oxygenates alters the stoichiometric air/fuel ratio. Provided the carburetor setting is unchanged, this may reduce emissions of carbon monoxide (CO) and hydrocarbons (HC), but can also increase emissions of oxides of nitrogen (NOX). For further discussion, see OECD (1995). Because of cold start-up emissions, Burmich (1989) finds that a 5-mile trip has almost three times the emissions per mile as a 20-mile trip at the same speed. Sierra Research (1994) finds that a car driven aggressively has a carbon monoxide emissions rate that is almost 20 times higher than when driven normally.

5 As noted by Innes (1996, pp. 226-7), "Even if only a small proportion of consumers cheat in this way, those who cheat are likely to be those who drive the most, who therefore have the greatest incentive to cheat and who are arguably the most important targets of mileage taxation."

${ }^{6}$ Harrington et al. (1998) analyze maintenance incentive programs. Fullerton and West (2000) show that if households do not gain utility from PCE or fuel cleanliness, then the optimal policy combination includes a subsidy of $100 \%$ of the costs of these goods. In that case, computing optimal subsidies using household data would be a meaningless exercise. Mandates might work better. Using homogeneous consumers, Eskeland (1994) shows how the effects of the optimal Pigovian tax can be matched by the combination of a mandated emissions rate and a gas tax. 
is, when we estimate the effect of vehicle age on the emissions rate, we are largely estimating the effect of increasingly-stringent emissions standards over time. To the extent that these standards have made new cars more expensive, however, they may actually discourage the purchase of the newer, cleaner cars. Those existing regulations are given, for our model, and so our calculated second-best subsidy to newer cars should be interpreted as a way to offset the extra expense of stricter mandates and thus to encourage the purchase of those cleaner vehicles.

One advantage of this numerical model is that it can evaluate simpler methods of deriving the "best" policy combination. One such method is to assume that all consumers are identical and therefore that all drive the same number of miles in cars of mean size and vintage. Indeed, if consumers really were identical, then the first-best (individually-tailored) tax rates would turn out to be uniform tax rates on gas, engine size, and vehicle age. We then ask how these rates perform in our model where consumers are not identical. The answer depends upon the degree of nonlinearity in the estimated $E P M$ and $M P G$ functions, and on the correlations between miles, size, and vehicle age. We find that means-evaluated tax rates achieve only 61.5 percent of the Pigovian welfare gain, less than that achieved by the uniform gas tax alone.

Section I describes the analytical model and closed-form solutions for first-best tax rates. All of the assumptions of that model are retained when Section II adds specific functional forms for the numerical model. Section III describes the data and the derivation of parameters. Section IV uses this model to calculate welfare-maximizing uniform tax rates on gasoline, engine size, and vehicle age. It also compares welfare gains from using those second-best rates and from using means-evaluated tax rates. Section V concludes.

\section{The Analytical Model}

This simple economy consists of $n$ heterogeneous individuals, each of whom owns one vehicle. Some vehicle characteristics affect emissions (such as age and engine size) and other characteristics do not affect emissions (such as leather seats or a sunroof). These individuals buy 
gasoline in order to drive miles, and they buy other goods. In order to focus on consumer choices, we assume linear production with perfect competition, full information, and no market failures other than a negative externality from emissions. Thus producer prices are fixed (and consumer prices vary with tax rates). Tax revenue from individual $i$ is returned to the same individual in a lump sum, which is part of the individual's exogenous income, $y_{i}$.

Individuals get utility from driving miles $m_{i}$, from vehicle attributes, and from other goods, $x_{i}$. In addition, individual utility is affected by aggregate auto emissions, $E$. Thus:

$$
U_{i}=u_{i}\left(m_{i}, s_{i}, v_{i}, x_{i}\right)-\mu E
$$

where each $u$ is continuous, differentiable, and strictly concave. Because we are not concerned with differential benefits from environmental protection, we assume $\mu$ is the same for all consumers. This $\mu$ is the change in utility from an additional unit of emissions $(\partial U / \partial E)$. The composite commodity $x$ is numeraire and consists of all other goods purchased by the consumer, including vehicle attributes not associated with emissions.

The vehicle attributes $s$ and $v$ could be anything that affect both utility and emissions. For concreteness, we define $s$ as the size of the engine, in cubic inches of displacement (CID). Individuals also get utility from having a newer car, and so we define vintage, $v$, as a measure of "newness." Actual measurement of this variable is left for the numerical section below.

Each individual's emissions per mile depend on size and newness, $\operatorname{EPM} M_{i}=\operatorname{EPM}\left(s_{i}, v_{i}\right)$, and each individual generates $m_{i} \operatorname{EPM}\left(s_{i}, v_{i}\right)$ of emissions. Aggregate pollution is thus

$$
E=\sum_{i} m_{i} \operatorname{EPM}\left(s_{i}, v_{i}\right)
$$

As we find below, larger cars have higher emissions rates $\left(E P M_{s i} \equiv \partial E P M_{i} / \partial s_{i}>0\right)$, and newer cars have lower emissions rates $\left(E P M_{v i}<0\right)$. Also, fuel efficiency depends on the same two choice variables, so $M P G_{i}=\operatorname{MPG}\left(s_{i}, v_{i}\right)$. Cars with larger engines tend to get lower gas mileage 
$\left(M P G_{s i}<0\right)$, while newer cars tend to be more efficient $\left(M P G_{v i}>0\right)$.

Consumers do not purchase $m$ directly, but through the combination they choose of gasoline $(g)$, size $(s)$, and newness $(v)$. The demand for gasoline is related to desired $m$ by:

$$
g_{i}=\frac{m_{i}}{\operatorname{MPG}\left(s_{i}, v_{i}\right)}
$$

\section{A. Consumer Problem}

Consumers use equation (3) when they decide vehicle size and vintage and how much gasoline will maximize utility in equation (1) above. However, the individual does not recognize that his or her own emissions add to aggregate emissions $(E)$. We include the possibility that the individual is taxed or subsidized on consumption of $g, s, v$, and $x$. We also consider an ideal tax on emissions, $t_{E}$. The individual problem is to maximize (1) subject to a budget constraint:

$$
y_{i}=\left(\frac{\left(p_{g}+t_{g}\right)}{M P G\left(s_{i}, v_{i}\right)}\right) m_{i}-\left(p_{s}+t_{s}\right) s_{i}-\left(p_{v}+t_{v}\right) v_{i}-\left(1+t_{x}\right) x_{i}-t_{E} \operatorname{EPM}\left(s_{i}, v_{i}\right) m_{i}
$$

The price per gallon of gasoline is $p_{g}$, the tax per gallon is $t_{g}$, and the consumer's cost of gasoline in dollars per gallon is divided by miles per gallon to get a figure that is in dollars per mile. Then $p_{s}$ and $t_{s}$ represent the price and tax for adding an additional cubic inch of displacement to an engine. The price and tax per unit of newness are $p_{v}$ and $t_{v}$. The actual implementation of such a tax is left for discussion below. Finally, the price of $x$ is normalized to one, and $t_{x}$ is the tax per unit of $x$ (which turns out to be unnecessary). ${ }^{7}$

In this maximization, $\lambda_{i}$ is the individual's marginal utility of income (the multiplier on the budget constraint). First order conditions and other derivations for this first-best model are shown in an Appendix (available in the working paper or from the authors).

\footnotetext{
${ }^{7}$ A tax at the same rate on all expenditures $(g, s, v$, and $x$ ) is equivalent to the lump sum tax on exogenous income $y$, so any one tax is unnecessary and can be set to zero.
} 


\section{B. Social Planner's Problem}

The social planner maximizes a measure of social welfare such as a weighted sum of the individuals' utilities. To do this, we must specify weights. For present purposes, we want weights that meet three criteria. First, we want to abstract from the welfare effects of any pure redistribution and focus instead on comparing the efficiency of various policies. Therefore, we choose weights so that a dollar given to any individual has the same effect on social welfare. ${ }^{8}$ To achieve this condition, we divide each individual's utility by his or her own marginal utility of income $\left(\lambda_{i}\right)$. Second, when $t_{E}$ is available, we want the maximization of welfare to yield the solution of Pigou (1932). Since this solution is based on marginal conditions at the optimum, we use the values for $\lambda_{i}$ that occur at the first-best social optimum $\left(\lambda_{i}{ }^{*}\right)$. Third, we want to be able to compare policies using the same welfare weights and to find uniform tax rates that maximize the same social welfare function. Therefore we use prices at the Pigovian equilibrium to evaluate $\lambda_{i}{ }^{*}$, and we use those $\lambda_{i}{ }^{*}$ to get the weights $\left(1 / \lambda_{i}{ }^{*}\right)$ for all subsequent evaluations of other policies. The result is a money-metric measure of social welfare.

The social planner does recognize how individual decisions affect aggregate emissions, in equation (2), and maximizes social welfare subject to a resource constraint (the sum of all consumers' exogenous incomes). The multiplier on this resource constraint is $\delta$, the social marginal utility of income. In the Appendix, we compare the first-order conditions from this problem with those from the consumers' problem to derive the optimal emissions tax:

$$
t_{E}=\frac{n \mu}{\delta} \equiv M E D
$$

This is the traditional Pigovian tax, equal to the sum of all individuals' disutilities from

\footnotetext{
8 This assumption abstracts from important issues, but it can be partially justified by Mayeres and Proost (1997). They use an applied general equilibrium model that "demonstrates that the level of the externality tax does not depend strongly on distribution concerns, as reoptimization of the other taxes ensures that the income distribution objective is reached" (p. 261).
} 
emissions, $n \mu$, translated into monetary terms when divided by $\delta$, the social marginal utility of income. ${ }^{9}$ This tax is the aggregate monetary marginal environmental damages $(M E D)$.

This uniform emissions tax by itself induces all individuals, no matter their tastes for miles, size, and newness, to drive the optimal number of miles in cars of the right size and vintage. However, we are interested in alternative polices that do not require the measurement of emissions. In this model, the first best can also be achieved by an annual tax on vehicle $i$ equal to $n \mu m_{i} \operatorname{EPM}\left(s_{i}, v_{i}\right)$, but this tax depends on miles driven and thus requires tamper-proof odometers. ${ }^{10}$ Another policy that attains the first best is a gas tax that varies with the attributes of the vehicle at the pump (Fullerton and West, 2000). If the rate $t_{g}=n \mu m_{i} \operatorname{EPM}\left(s_{i}, v_{i}\right) M P G\left(s_{i}, v_{i}\right)$ is substituted into the maximization problem before differentiation, with all other tax rates equal to zero, then all first order conditions of the consumers match those of the social planner. However, individuals might siphon gas from a low-emissions car to a high-emissions car.

Given these enforcement problems, we assume here that the vehicle tax cannot depend upon miles, and the gas tax cannot vary with the vehicle at the pump. As shown in our appendix, the first best can still be achieved by a three-part-instrument (3PI) that involves individualspecific tax or subsidy rates on gasoline, engine size, and newness. These tax rates are:

$$
\begin{aligned}
& t_{g i}=n \mu E P M\left(s_{i}, v_{i}\right) M P G\left(s_{i}, v_{i}\right) \\
& t_{s i}=n \mu E P M_{s i} m_{i}+\frac{n \mu E P M\left(s_{i}, v_{i}\right) M P G_{s i} m_{i}}{M P G\left(s_{i}, v_{i}\right)} \\
& t_{v i}=n \mu E P M_{v i} m_{i}+\frac{n \mu E P M\left(s_{i}, v_{i}\right) M P G_{v i} m_{i}}{M P G\left(s_{i}, v_{i}\right)}
\end{aligned}
$$

\footnotetext{
${ }^{9}$ Because our weights were chosen to equate the social value of a dollar in each use, at the optimum, the social marginal utility of income is one. See the Appendix for a full explanation. ${ }^{10}$ See discussion in Mills and White (1978), Innes (1996), or Sevigny (1998).
} 
These rates do not vary with individual choices, but they must be set at a different rate for each individual based on that individual's own optimal choices $\left(m_{i}, s_{i}\right.$ and $\left.v_{i}\right) .{ }^{11}$ If individuals differ, information requirements are enormous. If individuals were identical, however, then the use of mean miles and vehicle attributes in (6) would yield first-best uniform tax rates. Thus the degree of heterogeneity determines the degree to which uniform rates based on using means in (6) will fall short of the first-best outcome. We quantify this shortcoming, below.

Some interpretations are in order. Note that the gas tax in (6a) charged to individual $i$ is the damage caused by an increase of one gallon used by that person. The size tax in (6b) has two components. The first term is the direct damage caused by one additional unit of size. If $E P M_{s i}$ $>0$, this term is positive. The second term is an indirect effect from adding size, through its effect on fuel efficiency. As long as $M P G_{s i}<0$, this term is negative and is thus a rebate. Specifically, it rebates what individuals already pay for their extra size through the gas tax.

The tax on newness (6c) is analogous to the size tax. If $E P M_{v i}<0$, then the first term is negative. It represents the value of the reduction in emissions due to a slightly newer car. The second term is the indirect effect from having a newer car through its effect on fuel efficiency. As long as $M P G_{v i}>0$, this term is positive. It is the portion of the external benefit of newness that is already internalized by paying less gas tax.

\section{The Numerical Model}

We now prepare to calculate second-best tax rates in the model above, keeping all of its notation and assumptions. In our data, if a household owns more than one vehicle, we assume that a different driver makes decisions regarding each vehicle type and miles driven. ${ }^{12}$ In other

${ }^{11}$ In other words, this individual maximization problem does not take derivatives of tax rates in (6) with respect to $m, s$, or $v$.

12 We assume that one driver does not affect the decisions made by another driver in the same household. Thus, we avoid making arbitrary assumptions about interdependence and economies of scale. This assumption is partially justified by a finding in Sevigny (1998) that "suggests that 
words, our unit of analysis is the individual. Each decision-maker maximizes his or her own utility subject to a budget. We assume a Constant Elasticity of Substitution (CES) form for $u_{i}$ :

$$
U_{i}=\left[\alpha_{i}^{\frac{1}{\sigma}} m_{i}^{\frac{\sigma-1}{\sigma}}+\beta_{i}^{\frac{1}{\sigma}} \frac{\sigma-1}{{ }^{\frac{\sigma-1}{\sigma}}}+\gamma_{i}^{\frac{1}{\sigma}} v_{i}^{\frac{\sigma-1}{\sigma}}+\left(1-\alpha_{i}-\beta_{i}-\gamma_{i}\right)^{\frac{1}{\sigma}} x_{i}^{\frac{\sigma-1}{\sigma}}\right]^{\frac{\sigma}{\sigma-1}}-\mu E
$$

where $\sigma$ is the elasticity of substitution among the four private goods. For the special case where $\sigma$ is one, this CES specification reduces to the Cobb-Douglas form. While we still ignore differences in benefits of abatement $(\mu)$, we analyze heterogeneous driving choices and abatement costs by allowing the taste parameters $\alpha, \beta$, and $\gamma$ to differ across individuals.

For numerical results below, we derive and use the CES demands from maximization of (7) subject to the budget constraint (4). For a more intuitive exposition here, however, we show only the demands that result from using the Cobb-Douglas version of (7). Even this simple form generates complex demand functions (subscripts for individual $i$ are suppressed): ${ }^{13}$

$$
\begin{aligned}
& m=\frac{\alpha\left[y-\frac{s m\left(p_{g}+t_{g}\right) M P G_{s}}{M P G(s, v)^{2}}-\frac{v m\left(p_{g}+t_{g}\right) M P G_{v}}{M P G(s, v)^{2}}+s m t_{E} E P M_{s}+v m t_{E} E P M_{v}\right]}{\frac{p_{g}+t_{g}}{M P G(s, v)}+t_{E} \operatorname{EPM}(s, v)} \\
& s=\frac{\beta\left[y-\frac{s m\left(p_{g}+t_{g}\right) M P G_{s}}{M P G(s, v)^{2}}-\frac{v m\left(p_{g}+t_{g}\right) M P G_{v}}{M P G(s, v)^{2}}+s m t_{E} E P M_{s}+v m t_{E} E P M_{v}\right]}{\left[p_{s}+t_{s}-\frac{m\left(p_{g}+t_{g}\right) M P G_{s}}{M P G(s, v)^{2}}+m t_{E} E P M_{s}\right]} \\
& v=\frac{\gamma\left[y-\frac{s m\left(p_{g}+t_{g}\right) M P G_{s}}{M P G(s, v)^{2}}-\frac{v m\left(p_{g}+t_{g}\right) M P G_{v}}{M P G(s, v)^{2}}+s m t_{E} E P M_{s}+v m t_{E} E P M_{v}\right]}{\left[p_{v}+t_{v}-\frac{m\left(p_{g}+t_{g}\right) M P G_{v}}{M P G(s, v)^{2}}+m t_{E} E P M_{v}\right]}
\end{aligned}
$$

the two-vehicle household is less likely to substitute between vehicles than previously expected. It may be that these households typically have a dedicated driver for each vehicle ..." (p. 35).

${ }^{13}$ The demand for $x$ is $(1-\alpha-\beta-\gamma)$ times the same bracketed term in the numerator, over $\left(1+t_{x}\right)$. 
This individual problem does not generate closed-form demands. Instead, demands are highly nonlinear and interrelated. ${ }^{14}$ Each demand (8a) through (8c) has all quantities $(m, s, v)$ on the right hand side, both in the numerator and in the denominator. In particular, the effective price of a mile (the denominator of the demand for miles) depends on $s$ and $v$, because $M P G$ depends on $s$ and $v$. Similarly, the effective cost of more size in (8b) includes not only the direct outlay $\left(p_{s}+t_{s}\right)$ but also the cost of extra gas needed, given a number of miles $m$, when using a larger car with lower $M P G$. The cost of an additional unit of $s$ also includes the cost of any extra emissions tax associated with it. Finally, the cost of buying more newness, $v$, depends on how it affects $M P G$ and on the intended number of miles, $m$. If newness increases $M P G$ and lowers $E P M$, then the last two terms in the denominator of (8c) reflect the lower gas costs and emissions taxes that must be paid.

Just as the effective price of each good must be adjusted, so must each individual's total expenditure - the amount in brackets in each numerator of (8). Total expenditure, $y$, is adjusted by the extra spending associated with the ways in which effective prices are adjusted (terms that account for the higher gas expenditures of a higher $s$, and the lower gas expenditures of a higher v). The last two terms account for the impact that $s$ and $v$ have on emissions taxes paid.

Given these individual demand behaviors, we want to find a set of uniform tax or subsidy rates $\left(t_{g}, t_{s}, t_{v}\right)$ that maximize social welfare. Assuming producer prices are fixed, this is equivalent to maximizing the weighted sum of indirect utilities:

$$
\sum_{i}\left[\frac{V\left(t_{g}, t_{s}, t_{v} ; \alpha_{i}, \beta_{i}, \gamma_{i}, y_{i}\right)}{\lambda_{i}{ }^{*}}-\mu E\right]
$$

Our programs iterate on various combinations of $\left(t_{g}, t_{s}, t_{v}\right)$ until (9) is maximized (using a project Lagrangian algorithm called MINOS, a solver in GAMS). In case only a subset of those three

\footnotetext{
${ }^{14}$ In the CES form, the denominator of each demand (8a-8c) includes a term involving all the goods' prices, so the CES demands are even more nonlinear and interrelated.
} 
tax rates is feasible, we also find the second-best rates for each pair, and for each tax alone. To rank these policies, we calculate the gain as a percentage of the gain from the first-best Pigovian tax. We also explore the effects of varying the elasticity of substitution, $\sigma$.

\section{Data and Parameter Derivations}

To implement this model, we need data on individual expenditures, prices, and each vehicle's size, newness, fuel efficiency, and emissions per mile. The three main sources of data used in this study are the Consumer Expenditure Survey (CEX), the California Air Resources Board (CARB, 1997) Light-Duty Surveillance Program, and the American Chamber of Commerce Researchers' Association (ACCRA, 1993 and 1994) cost-of-living index.

The 1994 CEX is published annually by the Bureau of Labor Statistics (1996); it provides detailed information on the quarterly expenditures of approximately 5000 households. Each household participates in the survey for five consecutive interview quarters. All CEX observations include the amount spent on gasoline as well as total expenditures. The 1994 survey also contains files with detailed information on each household's vehicles. Just a few of the variables included in the vehicle file are year, make, model, and number of cylinders. ${ }^{15}$ The CEX is a rotating panel survey, which means that 20 percent of the sample is rotated out, each quarter, and replaced by new households. We pool households across the four quarters in the 1994 CEX and treat each observation as a different household (ignoring the correlation across consecutive observations of the same household).

Between November 1995 and March 1997, the CARB tested the emissions per mile and fuel efficiency of 345 vehicles in California. They recorded numbers for emissions of

15 In addition, the vehicle file lists each vehicle's cumulative mileage. In order to obtain a number for miles driven in a quarter, we originally planned to match households across quarters and subtract the previous quarter's odometer reading from that of the current quarter. When we did this, however, we discovered that most odometer readings are rounded estimates. And, for 
hydrocarbons (HC), carbon monoxide (CO), and oxides of nitrogen (NOX). ${ }^{16}$ In addition, they compiled vehicle information such as make, model, year, number of cylinders, and cubic inches of displacement (CID). We drop the three motor homes, and 342 vehicles remain.

We then find vehicles in the CEX that match a CARB vehicle's make, model, year, and number of cylinders. This match enables us to use the CARB vehicle's CID as well as EPM and $M P G$ for any matching vehicle in the CEX. For single-car households in the CEX with complete expenditure and vehicle data, we obtain 567 usable matches. ${ }^{17}$ We also consider multicar CEX households with complete expenditure and vehicle data and at least one car matching an observation in the CARB. In very few of these cases do two or more cars of the same household match observations in the CARB. Thus, in order to retain a reasonable number of cars from multi-car households, we undertake a few imputations. For the remaining vehicles of those multi-car households, we use CARB data to estimate CID as a quadratic function of cylinders and newness, plus a dummy variable for trucks and vans. ${ }^{18}$ The final sample consists of 567

some households, the current quarter's odometer reading is less than that of the previous quarter. Thus we elected to derive miles using data to be described shortly.

16 The Light-Duty Vehicle Surveillance Program, Series 13, was part of ongoing efforts by the CARB to accumulate vehicle emissions data, to investigate vehicle maintenance practices, and to determine the frequency and effect of tampering with pollution control equipment. To undertake this project, the CARB chose a random sample of all vehicles in California, and then sent requests to owners of such vehicles within a 25-mile radius of the CARB office in El Monte, California. The final sample includes only those who responded, however, so it is not necessarily representative of all California. And since California standards were tougher than US standards from 1966 to 1993, our sample of cars is likely to be cleaner than US cars of that period. US standards have moved towards the stricter California standards, however, so perhaps our California sample from 1994 reflects current cleanliness for the whole United States.

${ }^{17}$ We started with a larger number of matches, but 27 were not used because gas expenditures were zero. One was not used because expenditure shares summed to more than one. Some other matches were dropped because GAMS could not solve the household's demand system due to the nonlinearity of the system in combination with that household's particular parameters.

18 The estimated regression used to impute displacement is (standard errors in parentheses): displacement $=-101.75+35.88$ cylinders +2.68 cylinders $^{2}+5.83$ newness -.06 newness $^{2}$

$$
\text { (49.48) (14.1) (1.07) }
$$

-.74newness* cylinders +26.08 truck/van dummy

$$
\text { \#obs }=342 \quad \mathrm{R}^{2}=.8753
$$


vehicles from one-vehicle CEX households and 694 vehicles from multi-vehicle CEX households. ${ }^{19}$ The driver from a one-car household is assigned the total expenditure for that household. For a multi-car household, total expenditure is divided by the number of vehicles.

To establish a baseline, we need to assign prices to gasoline, size, and newness. For gas prices, we use the ACCRA cost-of-living index. This index compiles prices of many goods in about 300 cities in the United States, and it is often used to calculate the difference in the overall cost-of-living between any two cities. It also lists average gasoline prices for each city in the survey each quarter. We average the city gas prices to obtain state gasoline prices for each calendar quarter. We then assign a gas price to each CEX household based on state of residence and CEX quarter, and we divide gas expenditures by this price to get gallons of gas consumed.

In order to simulate a scenario with no pre-existing gas taxes, we need to know the 1994 gas tax rates. The Federal gas tax was $\$ .184$ per gallon, and the average 1994 state gas tax was 19 cents per gallon (ORNL, 1996).

Ohta and Griliches (1986) provide the information necessary to calculate the price per cubic inch of displacement (CID). They use a hedonic semi-log regression of used car prices on car characteristics to obtain the estimate that an increase of one cubic inch of displacement increases price by $.253 \%{ }^{20}$ To translate their estimate into dollars per cubic inch in 1994 , we use the fact that the average price of a new car in 1994 was $\$ 19,676$ (ORNL, 1996, p. 2-38). ${ }^{21}$

19 Thus 45 percent of the vehicles in our final sample are from single-car CEX households and 55 percent are from multi-car households. Unfortunately, these percentages are not very close to those for the U.S. population: in the 1990 census, about a quarter of all vehicles are from singlecar households (ORNL, 1998: p. 10-8). We are unable to use more multi-car households from the available data, but we test the importance of this issue below by performing calculations for single-car households separately from multi-car households.

20 The t-statistic is 6.301. They use a sample of used cars from model years 1970-1980. This parameter is an estimate of the average implicit price for a marginal change in "size." We assume it is constant, though the price of the first cubic inch is likely to differ from the last.

${ }^{21}$ This average price is in 1994 dollars and includes prices of imported vehicles. 
Thus the initial outlay per CID in 1994 is $(\$ 19,676)(0.00253)=\$ 49.78$. The 1990 vehicle model year average survival rate is 13.7 years (ORNL, 1996, p. 3-9). To obtain a price per quarter for one CID, we find the amount that would be paid each quarter for 56 quarters with a present value of $\$ 50$, assuming a $5 \%$ annual interest rate. This price per CID is $\$ 1.23$ per quarter. $^{22}$

Newness is the counterpart of vehicle age. An arbitrarily "old" vehicle does not depreciate any further, and newer vehicles depreciate more than older vehicles, so the individual's "spending" on newness each year is the amount the car falls in value. We use the unit convention and assume that the price of newness is one. Therefore the "quantity" of newness purchased in a given year is the amount it depreciates that year. The exponential depreciation rate is assumed to be .20 per year. ${ }^{23}$ However, much of each vehicle's value and depreciation pertains to leather seats or other features not related to emissions. We want to use the same measure of emission-related newness for all vehicles, so we apply that depreciation rate to a base vehicle's value, the average value for a new vehicle. The approximate average price of a new vehicle from 1960 to 1994 is $\$ 15,000$, in 1994 dollars, so we assume that every new car's cost of newness is $(.2)(\$ 15,000)=\$ 3000$ in the first year, or $\$ 750$ per quarter (regardless of make or model). While an owner of any 1994 vehicle consumes 750 units of newness per quarter, an owner of any 1980 vehicle consumes only 26.38 units of newness per quarter. ${ }^{24}$

We used the CARB data to experiment with a variety of specifications for $M P G\left(s_{i}, v_{i}\right)$

22 This price per CID is affected by existing regulations such as the corporate average fuel economy (CAFE) standards and the gas-guzzler tax. We assume that this price $p_{s}$ is fixed, when we try each tax $t_{s}$, so we implicitly assume that these existing regulations are unchanged.

${ }^{23}$ Estimates of this rate range from .33 (Hulten and Wykoff, 1981; Jorgenson 1996) or .30 (Hulten and Wykoff, 1996) to .15, the rate implicit in the vehicle depreciation schedule currently used by the Bureau of Economic Analysis (authors' calculations based on a depreciation schedule provided by Arnold Katz, BEA). We use .20 because it falls between these bounds.

${ }^{24}$ This measure of newness misses heterogeneity both within and across model years. With these data, however, we cannot know the extent to which expensive cars also have more expensive emission control equipment (or the specific depreciation rate for that equipment). Also, clearly, the effect of newness on EPM depends on existing regulations, left unchanged. 
and $\operatorname{EPM}\left(s_{i}, v_{i}\right)$. For fuel efficiency, we settled on the quadratic form, which is simple yet nonlinear. To ensure that estimates of $E P M$ are positive, we use a semi-log specification. ${ }^{25}$ For our measure of $E P M$, we use a weighted sum of the three pollutants in our sample: $\mathrm{HC}, \mathrm{CO}$, and NOX. We weight each pollutant according to its contribution to $M E D$; in accordance with Small and Kazimi (1995), we assign the highest weight to NOX (.495), followed by HC (.405) and CO $(.10){ }^{26}$ Table 1 reports the results of these regressions.

Table 1: Regression Results for $M P G\left(s_{i}, v_{i}\right)$ and $\operatorname{EPM}\left(s_{i}, v_{i}\right)$

\begin{tabular}{c|cccccccc}
\hline $\begin{array}{c}\text { Depen- } \\
\text { dent } \\
\text { Variable }\end{array}$ & Constant & $\mathrm{CID}$ & $\mathrm{CID}^{2}$ & Newness & Newness & $\begin{array}{c}\text { Newness } \\
{ }^{*} \mathrm{CID}\end{array}$ & $\mathrm{R}^{2}$ & F-stat \\
\hline MPG & 34.15 & -.116 & .000147 & .0151 & -.0000143 & .0000007 & .77 & 221.8 \\
& $(.986)$ & $(.0088)$ & $(.000018)$ & $(.00332)$ & $(.0000037)$ & $(.00001)$ & & \\
$\ln (\mathrm{EPM})$ & 1.101 & .0040 & -.0000044 & -.00879 & .0000078 & -.000001 & .64 & 116.6 \\
& $(.252)$ & $(.0023)$ & $(.0000045)$ & $(.000849)$ & $(.0000009)$ & $(.000003)$ & & \\
\hline
\end{tabular}

Standard errors are in parentheses; the number of observations in each regression is 342 .

In the $M P G$ regression, all coefficient estimates except the interaction term are statistically significant at the one-percent level. In the EPM regression, the coefficients on newness, newness-squared, and the constant term are significant at the one percent level. The coefficient on CID is significant at the ten-percent level, but those on the square of CID and the interaction term are not significant.

These regressions provide several insights for the numerical model. First, using the means of CID and newness to evaluate derivatives, these regression results show that fuel efficiency decreases with size $\left(M P G_{s}<0\right)$ and increases with newness $\left(M P G_{v}>0\right)$. Second, emissions per mile increase with size $\left(E P M_{s}>0\right)$ and decrease with newness $\left(E P M_{v}<0\right)$. Third,

25 Estimates of $M P G$ obtained using the quadratic specification are positive for all simulated values of size and newness. For $E P M$, however, use of that form results in some negative values.

${ }^{26}$ Small and Kazimi (1995) do not calculate a value of $M E D$ for CO, but they say it is small, so we use 10 for $\mathrm{CO}$. We then use their MED estimates for $\mathrm{HC}$ and NOX to assign those weights. 
the coefficients on the squared variables indicate whether each function is concave or convex in each variable. As shown in Fullerton and West (2000), heterogeneity means that welfare gains from second-best tax rates compared to means-evaluated rates depend on the nonlinearity of $M P G$ and $E P M$. Results here show that both functions are nonlinear: $M P G$ is convex in size and concave in newness, while $E P M$ is convex in newness.

We use the estimated regressions to assign each vehicle with functions that provide $M P G$ and EPM, not only for baseline values of $s$ and $v$, but also for simulated changes in those choices. ${ }^{27}$ Then, to obtain baseline miles driven for each one-car household, we multiply $M P G$ by gallons of gas consumed. For each multi-car household, we need to allocate the one value for gas expenditure using miles driven and $M P G$ of each vehicle. We match each vehicle across CEX quarters and take the difference in quarterly odometer readings. We keep vehicles from households for which we have at least two vehicles with positive miles driven that quarter, assuming that vehicles with missing or negative miles are not used by the household. Then, we divide each miles number by the vehicle's estimated $M P G$ to get estimated gas consumption. We divide each vehicle's estimated gas consumption by the sum of all of the household's vehicles' estimated gas consumption to assign the proportion of gas used by each vehicle. Finally, we use these proportions to allocate the total gas consumption for that household. Each car's gas use is divided by that car's $M P G$ to get miles driven.

To assign preference parameters for each individual's utility function, we use calibration from observed demands and assigned prices. For any assumed value of $\sigma$, we use the CES

\footnotetext{
${ }^{27}$ Three points about these regressions. First, they could be estimated with more general forms such as using a dummy for light trucks or using dummies for each year, but the current forms have the advantage of providing continuous variables for size and age (in order to apply a tax to each). Second, remember that the 342 vehicles are probably not representative of all cars. Third, we use the resulting $M P G$ and $E P M$ as if they are "true" values, though they are estimated with error. We use many other parameters for which standard errors are not available, so it is not possible to use all of the errors on all parameters to calculate errors on our simulated results.
} 
demand corresponding to (8a) to solve backwards for the value of $\alpha_{i}$ that the individual must have had, while facing existing prices and taxes, to optimize by choosing the observed number of miles. Similarly, we use CES demands corresponding to (8b) and (8c) to solve for the $\beta_{i}$ and $\gamma_{i}$ that an individual must have had to optimize by choosing the observed size and newness.

Lastly, we need a number for marginal environmental damages, $M E D$. The literature includes many diverse estimates of the $M E D$ per unit of car pollution, ${ }^{28}$ but methodological issues preclude consensus. Moreover, $M E D$ for any given location may be very high or low in a way that depends on population density. We wish to avoid choosing among diverse estimates in the literature, and we wish to avoid limiting our model to one locale. Therefore we simply choose a value for $M E D$ that would result in an optimal gasoline tax close to that which already exists. We find that if $M E D$ is $\$ .0076$ per gram (and $\sigma=1$ ), then the second-best optimal gas tax is about 30 cents per gallon. ${ }^{29}$ In this way, we avoid discussion of the proper level of environmental protection, and instead focus on the proper mix of instruments.

Table 2 presents the means of parameter values calibrated at existing tax rates, when $\sigma=$ 1 , and it presents the means of choice variables in the zero-tax scenario.

When $\sigma=1$, the CES parameters are expenditure shares. The mean parameter for miles, 3 percent, matches the mean gas expenditure in the 1994 CEX. The sum of the mean car-related parameters $\left(\alpha_{i}+\beta_{i}+\gamma_{i}\right)$ is 0.14 , so the average driver allocates 14 percent of expenditure to gasoline, size, and newness. Since this figure excludes non-emission-related expenditures (such as a sunroof or leather seats), it corresponds well to that of the average CEX household, which

28 See for example Krupnick and Kopp (1988), Small and Kazimi (1995), or Wijetilleke and Karunaratne (1995). For estimates of other external costs of driving, including noise, congestion, and accident costs, see Greene et al. (1997).

${ }^{29}$ We assume that the individuals in our sample live and drive in an airshed with perfect mixing. If everyone in the airshed is equally affected by pollution, then the individual's $\mu$ would equal the $M E D$ for the entire airshed divided by population. For the purposes of this paper, we assign a value of $M E D / 1261$ to get $\mu$ for each individual in our welfare calculations. 
spends 19 percent of its income on total car expenses (including gasoline, vehicle purchases, maintenance, and other charges). The average vehicle in the 1994 sample is a 1988 model year, six-cylinder vehicle, driven 14,743 miles per year. On the national level in 1994, the average car was also a 1988 model year, driven 11,400 miles per year (ORNL, 1996, p. 3-11).

Table 2: Parameter and Variable Descriptions and Means (1261 individuals, $\sigma=1$ )

\begin{tabular}{cll}
\hline Parameters & \multicolumn{1}{c}{ Description } & Mean \\
\hline$y$ & Total quarterly expenditure (from CEX data) & 5011.37 \\
$\alpha_{i}$ & Miles parameter (derived from equation 8a) & .03 \\
$\beta_{i}$ & Cubic inches of displacement parameter (from 8b) & .07 \\
$\gamma_{i}$ & Newness parameter (from 8c) & .04 \\
$\left(1-\alpha_{i}-\beta_{i}-\gamma_{i}\right)$ & Composite commodity parameter & .86 \\
MED & Marginal environmental damages (\$/gram) & .0076 \\
$p_{g}$ & Price of gas after removing pre-existing taxes (\$/gallon) & .72 \\
$p_{s}$ & Price per cubic inch of displacement per quarter (\$/CID) & 1.23 \\
$p_{v}$ & Price of newness per quarter (\$/unit) & 1.00 \\
$p_{x}$ & Price per unit composite commodity (\$/unit) & 1.00 \\
Variables & & \\
\hline$m_{i}$ & Miles per quarter & 3685.8 \\
$s_{i}$ & Cubic inches of displacement & 166.45 \\
$v_{i}$ & Newness (depreciation per quarter) & 181.39 \\
$x_{i}$ & Composite commodity (all other goods) & 4455.5 \\
$g_{i}$ & Gallons of gasoline per quarter & 169.63 \\
$M P G\left(s_{i}, v_{i}\right)$ & Miles per gallon & 21.74 \\
$E P M\left(s_{i}, v_{i}\right)$ & Emissions per mile (in grams) & 2.04 \\
\hline
\end{tabular}

\section{Simulation Results}

\section{A. Eight Scenarios}

We use the data set just described to simulate eight different tax scenarios and a baseline. To obtain the baseline, we remove the pre-existing federal and state gas taxes and solve the model. The eight scenarios include the ideal Pigovian tax, the combination of all three taxes (on gas, size, newness), each pair of tax rates (with the third set to zero), and each tax rate alone. In each case, since government can levy lump-sum taxes and faces no revenue requirement, we take each individual's tax paid and add it back to that individual's exogenous income. In this way, 
we can examine income-neutral tax effects and focus primarily on substitution effects.

For each of the eight scenarios, we use the numerical model to find the allowable tax rates, positive or negative, that maximize welfare (given individual demands). Our theory predicts that the optimal Pigovian tax will be equal to $M E D$, which we have specified to be .0076 , and we use this fact to test that our model correctly implements the underlying theory. For the seven remaining scenarios, we set $t_{E}=0$ and solve for second-best combinations of uniform tax rates. Because the gas tax reduces miles most directly, we expect combinations that involve a gas tax to dominate those without.

Table 3 shows results for the Cobb-Douglas specification (where $\sigma=1$ ). For each policy, it lists the percentage improvement relative to the zero-tax scenario, and the welfare gain as a percent of the gain achieved by the Pigovian tax. ${ }^{30}$

Table 3: Simulation Results (1261 individuals, $\sigma=1$ )

\begin{tabular}{l|ccccccc}
\hline Scenario & & & & & & $\begin{array}{c}\text { \% Gain from } \\
\text { Zero-Tax }\end{array}$ & $\begin{array}{c}\text { of Pigovian } \\
\text { Tax Gain }\end{array}$ \\
\hline & $t_{E}$ & $t_{g}$ & $t_{s}$ & $t_{v}$ & Welfare & . \\
Pigovian Tax & .0076 & 0 & 0 & 0 & 6286201.7 & .2511 & 100.00 \\
Three-part & 0 & .267 & -.007 & -.107 & 6281712.3 & .1795 & 71.49 \\
Two-part \#1 & 0 & .268 & 0 & -.107 & 6281706.3 & .1794 & 71.45 \\
Two-part \#2 & 0 & .291 & -.004 & 0 & 6280270.1 & .1565 & 62.33 \\
Gas tax & 0 & .291 & 0 & 0 & 6280267.7 & .1565 & 62.31 \\
Two-part \#3 & 0 & 0 & -.023 & -.148 & 6273598.2 & .0501 & 19.96 \\
New subsidy & 0 & 0 & 0 & -.148 & 6273543.3 & .0493 & 19.61 \\
Size subsidy & 0 & 0 & -.020 & 0 & 6270501.3 & .0007 & .29 \\
Zero taxes & 0 & 0 & 0 & 0 & 6270455.4 & 0 & 0 \\
\hline
\end{tabular}

In accordance with Pigovian tax theory, our simulation program finds that $t_{E}=.0076$ improves welfare to the greatest extent. The optimal three-part instrument includes a 27 cent tax per gallon of gasoline, a 0.7 cent subsidy per cubic inch of displacement per quarter, and a 10.7

${ }^{30}$ Since we weight individual utility by $1 / \lambda_{i}{ }^{*}$, the change in money-metric social welfare is analogous to a compensating variation. The answers are in dollars of the Pigovian equilibrium. 
cent subsidy to newness per quarter. The fact that the size tax is negative emphasizes the importance of reducing miles driven. A subsidy to size increases engine size, which has a small positive effect on emissions per mile $\left(E P M_{s}>0\right)$ but a larger negative effect on fuel efficiency $\left(M P G_{s}<0\right)$. It thus raises the overall price per mile, and reduces miles driven. In other words, a small subsidy to size has a net negative effect on emissions through the decrease in miles driven. Despite the heterogeneity of the consumers in our model, the three-part instrument performs adequately well. These subsidies and tax, even at the same rate for all consumers, can attain approximately $71 \%$ of the gain in social welfare achieved by a Pigovian tax.

Table 4: Variable Means and Percent Emissions Reduction for each Scenario

\begin{tabular}{l|ccccc}
\hline Scenario & Miles & $\begin{array}{c}\text { Size } \\
(\mathrm{CID})\end{array}$ & Newness & $\begin{array}{c}\text { \% } \text { of Pigovian } \\
\text { Reduction }\end{array}$ & $\begin{array}{c}\text { Tax Emissions } \\
\text { Reduction }\end{array}$ \\
\hline Pigovian tax & 2850.0 & 169.22 & 204.00 & 42.70 & 100.00 \\
Three-part & 2692.9 & 168.36 & 202.68 & 32.12 & 75.22 \\
Two-part \#1: $\mathrm{t}_{\mathrm{g}}, \mathrm{t}_{\mathrm{v}}$ & 2697.5 & 167.41 & 202.68 & 32.11 & 75.20 \\
Two-part \#2: $\mathrm{t}_{\mathrm{g}}, \mathrm{t}_{\mathrm{s}}$ & 2627.1 & 168.60 & 182.18 & 28.79 & 67.42 \\
Gas tax & 2629.9 & 168.01 & 182.84 & 28.79 & 67.42 \\
Two-part \#3: $\mathrm{t}_{\mathrm{s}}, \mathrm{t}_{\mathrm{v}}$ & 3670.1 & 168.90 & 210.01 & 9.80 & 22.95 \\
Newness subsidy & 3696.7 & 165.74 & 210.01 & 9.65 & 22.60 \\
Size subsidy & 3675.5 & 167.66 & 181.35 & 0.06 & 0.14 \\
Zero taxes & 3685.8 & 166.45 & 181.39 & - & - \\
\hline
\end{tabular}

Before discussing the other scenarios in Table 3, we look at quantity changes associated with the Pigovian tax and three-part instrument. Table 4 shows the means of miles, size and newness, for each scenario, and the percentage emissions reduction. It shows that emissions are cut by $42.7 \%$ with the Pigovian tax, and by $32.1 \%$ with the three-part instrument. In the first two rows of this table, however, note that the Pigovian tax allows more average miles driven and more engine size. How then does it achieve more emissions reduction? The answer is that the emissions tax optimally induces the most miles reduction where it matters most (such as for those with dirty cars) and it optimally affects engine size where it matters most (such as for those who drive many miles). Thus the average miles and size do not need to fall as much to achieve 
greater emissions reduction. In contrast, the uniform tax rates are somewhat blunt instruments, providing the same incentives to all drivers. This result points out the importance of heterogeneity for the efficiency of the Pigovian solution.

We now turn back to Table 3 to look at the other scenarios. Because the size subsidy is so small, a two-part instrument involving a 27 cent gas tax and 10.7 cent subsidy to newness (Two-Part \#1) attains nearly the same welfare gain as the three-part instrument. The gas tax and size subsidy (Two-Part \#2) attains $62 \%$ of the maximum gain. A 29 cent gas tax alone also achieves about $62 \%$ of the gain from the ideal Pigovian tax. This gas tax alone dominates the combination of subsidies to size and newness, which emphasizes that miles reduction is the most direct way to cut emissions. Without a gas tax, the optimal newness subsidy becomes more negative, assuming more of the burden of reducing emissions.

\section{B. Discussion}

How big is the absolute size of these gains? Our money metric measure of welfare gain from the Pigovian tax is $\$ 12.49$ per individual per quarter. The gain over all individuals is $0.25 \%$ of the sum of individual income in the sample. ${ }^{31}$ Both the three-part and the first two-part instrument induce a welfare gain of about $\$ 8.92$ per individual, or a total over all individuals of $0.18 \%$ of the sum of individual income.

The added gain from the ideal Pigovian tax is the difference (\$3.57, or $0.07 \%$ of income). Thus, if the additional administrative costs of implementing a Pigovian tax are greater than $0.07 \%$ of the sum of all affected individuals' incomes, then the three-part and first two-part instrument may dominate the Pigovian tax. However, the distributional effects of the Pigovian tax and these other combinations may differ. The impacts of alternative tax scenarios may differ

31 This $0.25 \%$ welfare gain seems a small percentage, but note that the denominator is all of income. It is analogous to the area of a Harberger triangle from correcting this market distortion, and so we note that the magnitude is comparable to the often-cited Harberger (1966) finding that the welfare gain from wholesale reforms of corporate taxation is $0.5 \%$ of income. 
even further if household composition is taken into consideration. In addition, we assumed that our $\operatorname{EPM}\left(s_{i}, v_{i}\right)$ and $\operatorname{MPG}\left(s_{i}, v_{i}\right)$ functions generated the true emissions and fuel efficiencies of each car in the sample. Any error would change the relative gains from these instruments.

Under our assumptions, a gas tax of 29 cents per gallon yields $62 \%$ of the Pigovian tax improvement. Whether the government should elect to impose just a gas tax depends on the ease with which it could implement a newness subsidy. Such a subsidy could be paid to all vehicle owners each year, based on newness, or only upon the purchase of a brand-new vehicle. ${ }^{32}$ Aternatively, it could be implicitly assessed in an "accelerated vehicle retirement program" that buys up old vehicles, as examined in Alberini et al. (1995). ${ }^{33}$

Another alternative is the gas tax and size subsidy combination. A positive size tax is already incorporated into the U.S. gas guzzler tax that consumers must pay when purchasing an automobile that has an EPA fuel economy rating of less than 22.6 MPG. ${ }^{34}$ These gas guzzler tax schedules could be modified to reflect externalities from pollution: instead of indirectly taxing size through low $M P G$, this tax could be made to depend on emission rates. ${ }^{35}$

32 Our model assumes that the supply of vehicles of any size or newness is perfectly elastic (as for a small open economy, or one jurisdiction within a larger economy). At the other extreme, if the supply of vehicles is fixed, a newness subsidy might simply provide a capital gain for new vehicle owners and not affect emissions. In a closed economy with an elastic supply of brandnew vehicles, however, a subsidy to brand-new vehicles can eventually increase the numbers of all low-age cars. An appropriate extension to this paper would be to model the used car market.

33 If such a program buys up a set of old vehicles, then we might expect those former owners to buy other cars that are not quite as old, shifting all drivers to somewhat newer cars (just as would the newness subsidy in our model).

${ }^{34}$ For example, a tax of $\$ 1,000$ is assessed on all automobiles whose fuel economy is between 22 and 22.5 MPG. This existing tax increases in a nonlinear fashion and reaches a maximum of $\$ 7,700$ for a vehicle with fuel efficiency rating under $12.5 M P G$. In 1996, the Federal government collected only $\$ 53$ million in gas guzzler taxes (ORNL, 1998, p. 6-15, 6-16).

35 Indeed, if both $s$ and $v$ are observable, then authorities can impose a vehicle tax that is a nonlinear function of $s$ and $v$. This tax could reflect the $\operatorname{EPM}(s, v)$ function. Use of this nonlinear vehicle tax schedule (together with a uniform gas tax) could generate a welfare gain that is a greater percentage of the Pigovian gain. 


\section{Sensitivity Analysis}

The relative welfare gains discussed in the previous section result from simulations using our baseline assumptions. In this section, we evaluate the robustness of those results by doing the same simulations under alternative assumptions. First, our basic model above employs all available CEX data from households that had at least one car that matched the CARB data. However, these 1261 cars did not include a representative number of multi-car households. To see how much difference this makes, we now run all simulations for just the 567 single-car households. The gain from the three-part instrument (and first two-part instrument) are now 67 percent of the Pigovian gain instead of 71 percent. None of the other results differ by more than 5 percentage points, and all eight tax combinations are ranked in the same order. Thus we conclude that the additional multi-car households do not make a big difference.

Second, we used an arbitrary value for marginal environmental damages (MED) in order to avoid choosing among diverse estimates in the literature and to avoid choosing a particular geographic location. We now vary the MED, and we find that all second-best optimal tax rates vary in almost the same proportion. That is, doubling the MED essentially doubles all secondbest tax rates. ${ }^{36}$ Thus, for any given estimate of damages, our results can be used to help set the mix of second-best instruments such as uniform taxes on gas or vehicle characteristics.

Third, our basic model uses an elasticity of substitution among goods, $\sigma$, equal to one.

We now undertake the same simulations using a lower value of $\sigma(.5)$, and a higher value (1.5). Relative welfare gains using all three values are listed in Table 5.

Note two characteristics of these results. First, relative to the zero-tax scenario, the gains in welfare from all policies increase with $\sigma$. As individuals are allowed to substitute more easily

\footnotetext{
${ }^{36}$ When $\mathrm{MED}=.0038$, second-best tax rates are $\mathrm{t}_{\mathrm{g}}=.140, \mathrm{t}_{\mathrm{s}}=-.006$, and $\mathrm{t}_{\mathrm{v}}=-.066$, with a welfare gain equal to 67 percent of the Pigovian gain. Thus, in Table 3, a doubling of MED to .0076 yields $\mathrm{t}_{\mathrm{g}}=.267, \mathrm{t}_{\mathrm{s}}=-.007$, and $\mathrm{t}_{\mathrm{v}}=-.107$ (and gain equal to 71 percent of Pigovian gain).
} 
among goods, all policies reduce emissions at a lower cost. Second, the welfare gains from the alternative policies relative to the Pigovian gain also increase with the elasticity of substitution.

But the rankings of the policies are identical for all values of $\sigma$. So, while welfare gains are sensitive to the elasticity of substitution, the choice among instruments is not. ${ }^{37}$

Table 5: Sensitivity Analysis

\begin{tabular}{l|cccccc}
\hline & \multicolumn{2}{|c}{$\sigma=.5$} & & $\sigma=1.0$ (from Table 3) & \multicolumn{2}{c}{$\sigma=1.5$} \\
\multicolumn{1}{c}{ Scenario } & $\begin{array}{c}\text { \% Gain } \\
\text { from } \\
\text { Zero-tax }\end{array}$ & $\begin{array}{c}\text { \% of } \\
\text { Pigovian } \\
\text { Gain }\end{array}$ & $\begin{array}{c}\text { \% Gain } \\
\text { from } \\
\text { Zero-tax }\end{array}$ & $\begin{array}{c}\text { \% of } \\
\text { Pigovian } \\
\text { Gain }\end{array}$ & $\begin{array}{c}\text { \% Gain } \\
\text { from } \\
\text { Zero-tax }\end{array}$ & $\begin{array}{c}\text { \% of } \\
\text { Pigovian } \\
\text { Gain }\end{array}$ \\
\hline Pigovian Tax & .1185 & 100 & .2511 & 100 & .4409 & 100 \\
Three-part & .0802 & 67.70 & .1795 & 71.49 & .3211 & 73.05 \\
Two-part \#1: $\mathrm{t}_{\mathrm{g}}, \mathrm{t}_{\mathrm{v}}$ & .0800 & 67.49 & .1794 & 71.45 & .3153 & 71.49 \\
Two-part \#2: $\mathrm{t}_{\mathrm{g}}, \mathrm{t}_{\mathrm{s}}$ & .0694 & 58.54 & .1565 & 62.33 & .2780 & 63.05 \\
Gas tax & .0692 & 58.40 & .1565 & 62.31 & .2773 & 62.90 \\
Two-part \#3: $\mathrm{t}_{\mathrm{s}}, \mathrm{t}_{\mathrm{v}}$ & .0189 & 15.93 & .0501 & 19.96 & .1075 & 24.38 \\
Newness subsidy & .0189 & 15.90 & .0493 & 19.61 & .1036 & 23.49 \\
Size subsidy & .0001 & .11 & .0007 & .29 & .0038 & .86 \\
Zero-taxes & 0 & 0 & 0 & 0 & 0 & 0 \\
\hline
\end{tabular}

\section{The Advantages of Incorporating Heterogeneity}

We undertook the simulations described above in order to incorporate heterogeneity into our optimal tax problem. But how much does heterogeneity matter? Before showing numerical magnitudes, we first describe logically how heterogeneity impacts optimal taxes thorough the concavity or convexity of the $E P M$ or $M P G$ functions, or though the correlation among miles,

${ }^{37}$ For each value of $\sigma$, we use our model to vary each price slightly and calculate demand elasticities. When $\sigma$ rises from 0.5 to 1.0 , the absolute value of the gasoline demand elasticity rises from 0.49 to 0.96 . In general, own-price elasticities are proportional to $\sigma$, while crossprice elasticities remain very small (absolute values less than 0.04). Most empirical studies reviewed by Dahl and Sterner (1991) or Espey (1996) find gasoline demand elasticities around 0.5 or less, but Sevigny (1998) finds it to be 0.85 to 0.94 . In any case, Table 5 shows that $\sigma$ does not much affect the percent of the Pigovian gain, or the ranking of policies. 
size and newness. These nonlinearities or correlations render the use of means-evaluated tax rates sub-optimal and increase the usefulness of computational models. Table 6 summarizes the types of nonlinearities that we found when we estimated the $M P G$ and $E P M$ functions.

Table 6: Nonlinearity of $M P G$ and $E P M$

\begin{tabular}{c|cc}
\hline \multirow{2}{*}{ Function } & \multicolumn{2}{|c}{ Argument } \\
\cline { 2 - 3 }$M P G$ & convex & concave \\
$E P M$ & -- & convex \\
\hline
\end{tabular}

Consider equation (6a), which says that the first-best individual-specific gas tax rate is $t_{g i}$ $=n \mu m_{i} \operatorname{EPM}\left(s_{i}, v_{i}\right) M P G\left(s_{i}, v_{i}\right)$. The fact that fuel efficiency is convex in size increases the weighted average of $M P G\left(s_{i}, v_{i}\right)$ relative to $M P G$ evaluated at mean size and newness, and thus increases the gas tax rate under heterogeneity relative to the rate in (6a) evaluated at the observed means. However, since fuel efficiency is also concave in newness, the second-best gas tax rate under heterogeneity is decreased relative to (6a) evaluated at the means. The fact that emissions per mile is convex in newness increases the weighted average of $E P M\left(s_{i}, v_{i}\right)$ relative to $E P M$ at the means, and thus increases the gas tax rate under heterogeneity relative to (6a) at the means. Similar effects operate on the tax rates for size and newness in equations (6b) and (6c).

Table 7: Correlation Matrix for Observed Values

\begin{tabular}{c|ccc}
\hline & Miles & CID & Newness \\
\hline Miles & 1.0000 & & \\
CID & -.2737 & 1.0000 & \\
Newness & .1716 & -.1186 & 1.0000 \\
\hline
\end{tabular}

These tax rates are further affected by any correlation among miles, size, and newness. Table 7 shows the estimated correlations - all significantly different from zero. The table shows that individuals who drive more miles tend to have smaller cars and newer cars. Indeed, large engines tend to come on older cars. The fact that $s$ and $v$ are negatively correlated affects the 
average $\operatorname{MPG}\left(s_{i}, v_{i}\right)$ or $\operatorname{EPM}\left(s_{i}, v_{i}\right)$ relative to the values at mean size and newness. It thus affects each tax rate under heterogeneity relative to the rate in (6) evaluated at the observed means. We cannot predict the net effects of these correlations on the second-best uniform tax rates.

Table 8: Means-Evaluated Rates and Second-Best Rates

\begin{tabular}{c|cc}
\hline Tax Rate & $\begin{array}{c}\text { Value at Means } \\
\text { (from Eq. 6) }\end{array}$ & $\begin{array}{c}\text { Second Best Rates } \\
\text { (from Table 3) }\end{array}$ \\
\hline$t_{g}$ & .208 & .267 \\
$t_{s}$ & -.029 & -.007 \\
$t_{v}$ & -.204 & -.107 \\
\hline
\end{tabular}

What are the net effects of these various forces? Table 8 shows that all second-best tax rates are higher than the rates evaluated at the means. The rate on gasoline is more positive, and the other two rates are less negative. If policymakers ignore heterogeneity and assume that everybody drives the same kind of car the same number of miles, then they would set the tax rates too low (relative to the second-best rates). They would also achieve less welfare gain. The use of rates from (6) evaluated at observed means obtains 61.5 percent of the Pigovian gain, compared with 71.5 percent under the second-best optimal three-part instrument.

\section{Conclusions}

In this paper, we solve for a variety of combinations of second-best uniform taxes on gasoline, engine size, and vehicle age using data from the 1994 Consumer Expenditure Survey, the California Air Resources Board, and the ACCRA Cost of Living Indexes. We thus combine information on 1261 individuals' expenditures with other information on vehicle characteristics including engine size, vintage, fuel efficiency, and emissions per mile.

We use engine size and vehicle age as the main determinants of emissions per mile, while gasoline demand and fuel efficiency determine miles driven. We then calculate second-best optimal tax or subsidy rates for eight different policy combinations. However, we have excluded 
other individual choices that impact vehicle emissions, such as the choice of pollution-control equipment and its maintenance, fuel cleanliness, the frequency of cold-start-ups, and driving aggressiveness. If data on individuals' choices for these activities become available, we could expand this numerical model to include them. Then, to affect emissions without a direct tax on emissions, the model would require a tax or subsidy to each of these additional choices.

We also ignore the interdependencies in a multi-car household's choice of miles for each vehicle. In our model, a gas tax causes all drivers in the household to drive fewer miles. In general, however, a gas tax may cause a household to drive fewer miles in their old gas-guzzler and more miles in their newer, more fuel-efficient car. Allowing for substitution among vehicles within the household might enable the same emissions reduction to occur at a lower cost to the household, and welfare gains of our simulated policies might be higher. ${ }^{38}$

In addition, we do not explicitly incorporate pre-existing policies such as the CAFE standards, the gas-guzzler tax, or emissions standards. These policies are embodied in the estimated functions for $M P G(s, v)$ and $\operatorname{EPM}(s, v)$. Without these standards, our alternative instruments would not perform as they do. The gas-guzzler tax indirectly taxes engine size and thus affects the magnitude of the optimal uniform tax on size in our model. Also, CAFE standards change the effect that vehicle age and size have on fuel efficiency, so they affect the magnitudes of all our tax rates. The subsidy to newer cars is effective in our model because emissions standards have become increasingly stringent. A more complete numerical implementation would explicitly model existing and potential mandates and incentives.

We simulate a zero-tax scenario, and the gain from a first-best Pigovian tax on emissions. For each second-best policy combination, we calculate the optimal rates, the welfare gain relative to the zero-tax scenario, and that gain as a percentage of the Pigovian gain. Despite the

${ }^{38}$ Green and $\mathrm{Hu}$ (1985) find that this kind of substitution occurs to a large extent in some households, but that its overall effect is negligible. Sevigny (1998) finds small effects. 
considerable heterogeneity in our data, two combinations of uniform tax rates perform well. We find that 71 percent of the Pigovian gain can be achieved by the three-part instrument involving a gas tax, a size subsidy, and a new-car subsidy. The two-part instrument involving a tax on gasoline and subsidy to newer cars also attains about 71 percent of the Pigovian gain. Adding the size subsidy to this two-part instrument does not significantly increase welfare because of the small impact that engine size has on EPM. A gas tax alone reaches 62 percent of the gains from an ideal Pigovian tax. These results are robust to variation in the elasticity of substitution among goods. The ultimate choice of policy depends on these welfare effects, on distributional effects not measured here, and on administrative costs of implementing each tax or subsidy. 


\section{References}

Alberini, Anna, Winston Harrington, and Virginia McConnell. "Determinants of Participation in Accelerated Vehicle-retirement Programs." The Rand Journal of Economics 26 (Spring 1995): 93-112.

American Chamber of Commerce Researchers Association (ACCRA). Cost of Living Index (Alexandria, VA: ACCRA, 1993 and 1994).

Bradsher, Keith. "Favors Benefit Light Trucks, But May Be Harmful." The Austin AmericanStatesman (December 7, 1997): A25, A42, A43.

Bureau of Labor Statistics (BLS). 1994 Consumer Expenditure Interview Survey Documentation (Washington, DC: Bureau of Labor Statistics, 1996).

Burmich, Pam. "The Air Pollution-Transportation Linkage." (Sacramento, CA: State of California Air Resources Board, Office of Strategic Planning, 1989).

California Air Resources Board (CARB). Test Report of the Light-Duty Vehicle Surveillance Program, Series 13 (LDVSP13) Project (September 3, 1997).

Dahl, Carol and Thomas Sterner. "Analyzing Gasoline Demand Elasticities: A Survey.” Energy Economics 13 (July 1991): 203-210.

Eskeland, Gunnar. "A Presumptive Pigovian Tax: Complementing Regulation to Mimic an Emissions Fee.” World Bank Economic Review 8.3 (1994): 373-394.

Eskeland, Gunnar and Shantayanan Devarajan. Taxing Bads by Taxing Goods: Pollution Control with Presumptive Charges (Washington, DC: The World Bank, 1996).

Espey, Molly. "Explaining the Variation in Elasticity Estimates of Gasoline Demand in the United States: A Meta-Analysis.” The Energy Journal 17 (1996): 49-60.

Fullerton, Don and Sarah West. "Can Taxes on Cars and on Gasoline Mimic an Unavailable Tax on Emissions?” NBER Working Paper No. 7059 (revised, 2000).

Greene, David L. and Patricia S. Hu. "The Influence of the Price of Gasoline on Vehicle Use in Multi-vehicle Households." Transportation Research Record 988 (1985): 19-24.

Greene, David L., Donald W. Jones, and Mark A. Delucchi, eds. The Full Costs and Benefits of Transportation: Contributions to Theory, Method, and Measurement (Berlin: Springer, 1997).

Harberger, Arnold C. "Efficiency Effects of Taxes on Income from Capital," in Marian Krzyzaniak, ed., Effects of Corporation Income Tax: Papers Presented at the Symposium on Business Taxation (Detroit, MI: Wayne State University Press, 1966). 
Harrington, Winston, Virginia McConnell, and Anna Alberini. "Economic Incentive Policies under Uncertainty," in Roberto Roson and Kenneth A. Small, eds. Environment and Transport in Economic Modelling (Dordrecht, The Netherlands: Kluwer Academic Publishers, 1998).

Harrington, Winston, Margaret Walls, and Virginia McConnell. "Shifting Gears: New Directions for Cars and Clean Air." Discussion Paper 94-26-REV (Washington, DC: Resources for the Future, June 1994).

Hoel, Michael. "Emission Taxes versus Other Environmental Policies.” Scandinavian Journal of Economics 100, No. 1 (March, 1998): 79-101.

Hulten, Charles R. and Frank C. Wykoff. "The Measurement of Economic Depreciation," in Charles R. Hulten, ed., Depreciation, Inflation, and the Taxation of Income from Capital (Washington, DC: The Urban Institute Press, 1981).

Hulten, Charles R. and Frank C. Wykoff. "Issues in the Measurement of Economic Depreciation." Economic Inquiry 34 (January 1996): 10-23.

Innes, Robert. "Regulating Automobile Pollution Under Certainty, Competition, and Imperfect Information." Journal of Environmental Economics and Management 31 (September 1996): 219-239.

Jorgenson, Dale W. "Empirical Studies of Depreciation." Economic Inquiry 34 (January 1996): 24-42.

Kohn, Robert E. “An Additive Tax and Subsidy for Controlling Automobile Pollution.” Applied Economics Letters 3 (July 1996): 459-462.

Krupnick, Alan and Raymond Kopp. The Health and Agricultural Benefits of Reductions in Ambient Ozone in the U.S. Discussion Paper QE88-10 (Washington, DC: Resources for the Future, August 1988).

Mayeres, Inge and Stef Proost. "Optimal Tax and Public Investment Rules for Congestion Type of Externalities.” Scandinavian Journal of Economics 99, No. 2 (June, 1997): 261-279.

Mills, Edwin S. and Lawrence J. White. "Government Policies toward Automotive Emissions Control," in Ann F. Friedlander, ed. Approaches to Controlling Air Pollution (Cambridge, MA: The MIT Press, 1978).

Oak Ridge National Laboratory (ORNL) and Stacy Davis. Transportation Energy Data Book: Edition 18 (Oak Ridge, TN: Oak Ridge National Laboratory, 1998).

Oak Ridge National Laboratory (ORNL), Stacy Davis and David McFarlin. Transportation Energy Data Book: Edition 16 (Oak Ridge, TN: Oak Ridge National Laboratory, 1996).

Ohta, Makoto and Zvi Griliches. "Automobile Prices and Quality: Did the Gasoline Price Increase Change Consumer Tastes in the U.S.?" Journal of Business and Economic Statistics 4 (April 1986): 187-198. 
Organization for Economic Co-operation and Development (OECD). Motor Vehicle Pollution: Reduction Strategies Beyond 2010 (Paris: OECD, 1995).

Pigou, Arthur C. The Economics of Welfare. Fourth edition (London: MacMillan and Co., 1932).

Plaut, Pnina. "The Comparison and Ranking of Policies for Abating Mobile-Source Emissions." Transportation Research D 3 (July 1998): 193-205.

Sevigny, Maureen. Taxing Automobile Emissions for Pollution Control (Cheltenham, UK and Northhampton, MA: Edward Elgar Publishing Ltd., 1998).

Sierra Research. "Analysis of the Effectiveness and Cost-Effectiveness of Remote Sensing Devices." Report SR94-05-05, prepared for the U.S. Environmental Protection Agency (Sacramento, CA: Sierra Research, 1994).

Small, Kenneth A. and Camilla Kazimi. "On the Costs of Air Pollution from Motor Vehicles." Journal of Transport Economics and Policy 29 (January 1995): 7-32.

United States Environmental Protection Agency (USEPA). National Air Pollutant Emission Estimates 1940-1987. EPA-450/4-88-022, Office of Air Quality Planning and Standards, Technical Support Division, National Air Data Branch (Research Triangle Park, NC: USEPA, 1989).

Wijetilleke, Lakdasa and Suhashini Karunaratne. Air Quality Management: Considerations for Developing Countries. World Bank Technical Paper 278, Energy Series (Washington, DC: The World Bank, 1995). 
Appendix

This appendix provides complete derivations for our analytical model. We expand the model in Fullerton and West (2000) to include vehicle vintage, v, called "newness." This variable rises for newer cars, so it increases utility and decreases emissions rates.

\section{A. The Individual's Problem}

The individual's problem is to maximize the Lagrangean

$$
\begin{aligned}
& u_{i}\left(m_{i}, s_{i}, v_{i}, x_{i}\right)-\mu E \\
& +\lambda_{i}\left[y_{i}-\left(\frac{\left(p_{g}+t_{g}\right)}{M P G\left(s_{i}, v_{i}\right)}\right) m_{i}-\left(p_{s}+t_{s}\right) s_{i}-\left(p_{v}+t_{v}\right) v_{i}-\left(1+t_{x}\right) x_{i}-t_{E} \operatorname{EPM}\left(s_{i}, v_{i}\right) m_{i}\right]
\end{aligned}
$$

with respect to $m_{i}, s_{i}, v_{i}$ and $x_{i}$. The consumer takes total emissions, $E$, as fixed. First order conditions for this problem are:

$$
\begin{aligned}
& \frac{\partial u_{i}}{\partial m_{i}}=\lambda_{i}\left[\left(\frac{p_{g}+t_{g}}{M P G\left(s_{i}, v_{i}\right)}\right)+t_{E} \operatorname{EPM}\left(s_{i}, v_{i}\right)\right] \\
& \frac{\partial u_{i}}{\partial s_{i}}=\lambda_{i}\left[p_{s}+t_{s}+m_{i}\left(\frac{-\left(p_{g}+t_{g}\right) M P G_{s i}}{M P G\left(s_{i}, v_{i}\right)^{2}}\right)+t_{E} E P M_{s i} m_{i}\right] \\
& \frac{\partial u_{i}}{\partial v_{i}}=\lambda_{i}\left[p_{v}+t_{v}+m_{i}\left(\frac{-\left(p_{g}+t_{g}\right) M P G_{v i}}{M P G\left(s_{i}, v_{i}\right)^{2}}\right)+t_{E} E P M_{v i} m_{i}\right] \\
& \frac{\partial u_{i}}{\partial x_{i}}=\lambda_{i}\left[1+t_{x}\right]
\end{aligned}
$$

Emissions can be made relevant to the consumer problem through the pollution tax $t_{E}$. The effective price per mile would then include the emissions tax per mile. Similarly, the implicit prices of $s$ and $v$ include the change in the cost of gasoline from the change in $M P G$, plus the change in the emissions tax from the change in EPM.

\section{B. The Social Planner's Problem}

The social welfare function described in the text is the weighted sum of all individuals' utilities, where each weight is the inverse of the individual's marginal utility of income at the first-best social optimum:

$$
W=\iint_{\alpha} \int_{\beta} \int_{\gamma}\left[\frac{u[m, s, v, x ; \alpha, \beta, \gamma, y]}{\lambda^{*}}-\mu E\right] h(\alpha, \beta, \gamma, y) \partial \alpha \partial \beta \partial \gamma \partial y
$$


where individuals are distributed according to income $(y)$ and three different preference parameters used to represent their different preferences for miles $(\alpha)$, size $(\beta)$, and newness $(\gamma)$. These are weighting parameters in the Constant Elasticity of Substitution (CES) utility function used in the numerical model, but the current utility function in (A1) above is not limited to the CES form. The distribution $h(\alpha, \beta, \gamma, y)$ has positive support on $[\underline{\alpha}, \bar{\alpha}] \times[\beta, \bar{\beta}] \times[\gamma, \bar{\gamma}] \times[y, \bar{y}]$. The integral of this distribution over all four parameters is the population, $n$.

The social planner's problem is to maximize that social welfare function subject to a resource constraint, the integral over all individual budget constraints. However, the social planner does recognize how individual emissions affect aggregate emissions in

$$
E=\iint_{\alpha} \int_{\gamma} \int_{y}[m E P M(s, v)] h(\alpha, \beta, \gamma, y) \partial \alpha \partial \beta \partial \gamma \partial y
$$

Thus the social planner uses (A4) when maximizing the Lagrangean

$$
\begin{aligned}
& \iint_{\alpha} \int_{\gamma} \int_{y}\left[\frac{u[m, s, v, x ; \alpha, \beta, \gamma, y]}{\lambda^{*}}-\mu E\right] h(\alpha, \beta, \gamma, y) \partial \alpha \partial \beta \partial \gamma \partial y \\
&+\delta\left[\iint_{\alpha} \int_{\gamma} \int_{y}\left[y-\frac{p_{g}}{M P G(s, v)} m-p_{s} s-p_{v} v-p_{x} x\right] h(\alpha, \beta, \gamma, y) \partial \alpha \partial \beta \partial \gamma \partial y\right]
\end{aligned}
$$

with respect to each consumer's $m, s, v$, and $x$ (given their individual $\alpha, \beta, \gamma$, and $y$ ). The multiplier on the resource constraint is $\delta$, the social marginal value of income. To maximize (A5), we can ignore the outer integral to obtain the individual marginal conditions and then incorporate the impact an individual's choices have on emissions by differentiating the aggregate emissions term with respect to the individual's $m, s$, and $v$. The resulting first-order conditions for individual $i$ are:

$$
\begin{aligned}
& \frac{\left(\frac{\partial u_{i}}{\partial m_{i}}\right)}{\lambda_{i}^{*}}-n \mu \operatorname{EPM}\left(s_{i}, v_{i}\right)=\delta\left[\frac{p_{g}}{M P G\left(s_{i}, v_{i}\right)}\right] \\
& \frac{\left(\frac{\partial u_{i}}{\partial s_{i}}\right)}{\lambda_{i}^{*}}-n \mu m_{i} E P M_{s i}=\delta\left[p_{s}+m_{i}\left(\frac{-p_{g} M P G_{s i}}{M P G\left(s_{i}, v_{i}\right)^{2}}\right)\right] \\
& \frac{\left(\frac{\partial u_{i}}{\partial v_{i}}\right)}{\lambda_{i}^{*}}-n \mu m_{i} E P M_{v i}=\delta\left[p_{v}+m_{i}\left(\frac{-p_{g} M P G_{v i}}{M P G\left(s_{i}, v_{i}\right)^{2}}\right)\right] \\
& \frac{\left(\frac{\partial u_{i}}{\partial x_{i}}\right)}{\lambda_{i}^{*}}=\delta
\end{aligned}
$$


The first term in each equation represents the individual's money value of marginal utility from each good. The second term in (A6a) represents the external cost of an additional mile driven by individual $i$. Similarly, the second terms in (A6b) and (A6c) represent the external cost of an additional unit of size and newness purchased by individual $i$. The first-order conditions (A6) say that the money-metric social marginal utility of each good is set equal to the social marginal cost of that good. Also, looking at (A6d), note that the left-hand side equals individual $i$ 's change in utility from an additional unit of $x$, divided by the marginal utility of income at the optimum. In other words, it is the dollar value of another unit of $x$ (the price of $x$ ). Since the price of $x$ equals one, (A6d) says that the social marginal utility of income, $\delta$, also equals one at the optimum.

\section{Solutions}

\section{The Pigovian Tax}

To solve for a Pigovian tax, set all taxes except $t_{E}$ equal to zero $\left(t_{s}=t_{v}=t_{g}=t_{x}=0\right)$ in equations (A2). Then, using $\delta=1$, (A6d) and (A2d) match each other. Also using $\delta=1$, set (A6a) and (A2a) equal to each other. The individual-specific variables drop out, leaving the traditional uniform Pigovian tax

$$
t_{E}=\frac{n \mu}{\delta} \equiv M E D
$$

Using $\delta=1$ and this value of $t_{E}$, the first order conditions for size (A6b and A2b) match each other, as do the first order conditions for newness (A6c and A2c). Since the consumer problem (A2) then attains the first-best social optimum, we have $\lambda_{i}=\lambda_{i}{ }^{*}$.

\section{First-Best Taxes on Gasoline, Size, and Newness}

If the measurement of emissions were difficult or impossible, so that $t_{E}=0$, we can find a different policy combination that attains the same efficient outcome. This policy is a three-part instrument that begins with a tax on gasoline and is complemented by taxes (or subsidies) on size and newness. To solve for these policy parameters, set $t_{x}=t_{E}=0$. Using $\delta=1$, we have equality between (A6d) and (A2d).

To solve for the tax on gasoline, plug $\delta=1$ into (A6a). Then subtract (A6a) from (A2a) to obtain equation (6a) in the text. To obtain the tax on size, plug $\delta=1$ into (A6b) and the gas tax into (A2b). Then subtract (A2b) from (A6b) to obtain equation (6b) in the text. We solve for the tax on newness in the same way as the size tax, to obtain $(6 \mathrm{c})$. 